\title{
INFLUENCIA DO TEOR DE AUSTENITA REVERSA NA CORROSÃO DO AÇO SUPERMARTENSÍTICO
}

\section{THE INFLUENCE OF REVERSE AUSTENITE ON SUPERMARTENSITIC STEEL CORROSION}

\author{
M. M. FRAGA ${ }^{1}$, R. S. BRAGA ${ }^{1}$, W. R. da C. CAMPOS ${ }^{2}$, J. D. ARDISSON² e V. de F. C. \\ LINS $^{1}$ \\ ${ }^{1}$ Universidade Federal de Minas Gerais, Departamento de Engenharia Química, Brasil \\ ${ }^{2}$ Centro de Desenvolvimento da Tecnologia Nuclear CDTN, Brasil \\ E-mail: maryfraga.5@gmail.com
}

article info

Article history:

Received 2017-09-04

Accepted 2017-11-20

Available online 2017-12-20
PALAVRAS-CHAVE: Aço supermartensítico; Corrosão; Austenita Reversa; Deformação plástica. KEYWORDS: Supermartensitic steel; Corrosion; Reversed Austenite; Plastic Deformation.

RESUMO: Aços supermartensiticos tem sido amplamente aplicados em indústrias, especialmente no setor de petróleo e gás, devido à boa relação custo benefício que apresentam. São aços inoxidáveis martensíticos com teores de cromo entre 11 e 13\% em massa, baixo teor de carbono intersticial e adições de níquel, molibdênio e em alguns casos, titânio e nióbio. Através de tratamentos térmicos de têmpera e revenimento, as propriedades desse aço são otimizadas, impactando diretamente na microestrutura, composta por martensita revenida $e$ pequenas quantidades de austenita reversa. Esse trabalho visa estudar a influência do teor de austenita reversa, obtida pela variação dos parâmetros do tratamento térmico nas propriedades de resistência à corrosão do aço em meio de tampão borato. Foram realizados testes de polarização cíclica e de espectroscopia de impedância eletroquímica. A caracterização do aço foi realizada por difração de raios-X e espectroscopia Mössbauer. Foi constatado que a preparação da amostra impactou diretamente nos teores de austenita reversa, o que também foi constatado pelo mesmo comportamento frente à corrosão para os aços com os diferentes teores iniciais de austenita.

\begin{abstract}
Supermartensitic steels have been widely applied in industries, especially in the oil and gas sector, due to the good cost-effectiveness that they present. They are martensitic stainless steels with chromium contents between 11 and $13 \mathrm{wt} . \%$, low interstitial carbon content and additions of nickel, molybdenum and, in some cases, titanium and niobium. Through quenching and tempering, the properties of this steel are optimized, impacting directly on the microstructure, composed of tempering martensite and small amounts of reverse austenite. This work aims to study the influence of the austenite content, obtained by the variation of the parameters in the heat treatment, on the corrosion resistance properties of the steel in borate buffer medium. Cyclic polarization and electrochemical impedance spectroscopy tests were performed. The characterization of the steel was performed by X-ray diffraction and Mössbauer spectroscopy. It was verified that the preparation of the sample impacted on the levels of austenite, causing even the same corrosion behavior of steels with the different initial austenite contents.
\end{abstract}




\section{INTRODUÇÃO}

Aços supermartensíticos são aços inoxidáveis martensíticos com teores de cromo entre 11 e $13 \%$ em massa, baixo teor de carbono intersticial, adições de níquel, molibdênio e em alguns casos, titânio e nióbio. Essa classe de aços inoxidáveis tem sido amplamente aplicada em indústrias, especialmente no setor de petróleo e gás, devido à boa relação custo benefício que apresentam. São mais resistentes à corrosão generalizada e à corrosão localizada na presença de $\mathrm{CO}_{2}$ (KONDO et al., 2002). Além disso, apresentam maior resistência e tenacidade quando comparados aos demais aços martensíticos (RODRIGUES et al., 2016). Essa excelente combinação de características acrescidas ao menor custo, tem contribuído para a substituição dos aços duplex por supermartensíticos em muitos casos (BARMOLA e BHINDER, 2015).

Devido ao baixo teor de carbono, a precipitação de carbetos de cromo é reduzida, com consequente aumento do cromo efetivo promovendo uma boa resistência à corrosão. Com o baixo teor de carbono, para evitar a formação de ferrita $\delta$ e manter a microestrutura martensítica após o resfriamento, níquel é adicionado para que a liga seja totalmente austenítica nas temperaturas de solubilização. Molibdênio é adicionado ao aço supermartensítico para melhorar a resistência à corrosão localizada e a corrosão sob tensão por sulfeto (KONDO et al., 1999).

As propriedades desse material são também otimizadas através de tratamentos térmicos de têmpera e revenimento durante sua fabricação. A microestrutura, basicamente composta por martensita revenida e pequenas quantidades de austenita retida e austenita reversa, é altamente dependente dos parâmetros do tratamento térmico (WEN et al., 2013). A austenita retida é proveniente da têmpera, em que parte do aço austenitizado não é transformado em martensita. Já a austenita reversa é obtida através do revenimento em temperaturas acima da temperatura de início da formação da austenita no aquecimento. Como a austenita reversa envolve o mecanismo de difusão, sua composição química é diferente da austenita retida. Enriquecida com níquel, carbono e nitrogênio, a austenita reversa permanece estável durante o resfriamento sendo mantida na microestrutura do material (DIAS, 2009).

Sabe-se que a austenita reversa, formada durante o revenimento, impacta diretamente as propriedades mecânicas do aço supermartensítico sendo capaz de aumentar a ductilidade da liga (BARMOLA e BHINDER, 2015). Em termos de corrosão, a presença de austenita reversa tem provocado uma melhora na resistência em alguns tipos de aço supermartensítico por reduzir a precipitação do cromo na forma de carbetos e tornar o filme passivo mais estável (LEI et al., 2016). O presente trabalho visa analisar a influência do teor de austenita reversa na resistência a corrosão do aço supermartensítico estudado.

\section{MATERIAL E MÉTODOS}

Três corpos de prova cúbicos de um aço supermartensítico com aproximadamente $1 \mathrm{~cm}^{2}$ de face foram utilizados no estudo. A composição química foi realizada usando a técnica de espectrometria de emissão ótica por plasma acoplado indutivamente e está apresentada na Tabela 1. 
Tabela 1 - Composição química do aço supermartensítico utilizado no estudo.

\begin{tabular}{cccccccccccc}
\hline Elemento & $\mathrm{C}$ & $\mathrm{Cr}$ & $\mathrm{Ni}$ & $\mathrm{Mo}$ & $\mathrm{Si}$ & $\mathrm{P}$ & $\mathrm{S}$ & $\mathrm{N}$ & $\mathrm{Ti}$ & $\mathrm{Al}$ & $\mathrm{Mn}$ \\
\hline \%massa & $<0,01$ & 12,2 & 5,63 & 1,86 & 0,21 & 0,023 & 0,004 & 0,026 & 0,17 & 0,015 & 0,52 \\
\hline
\end{tabular}

$\mathrm{O}$ três corpos de prova foram aquecidos à $1000^{\circ} \mathrm{C}$ e resfriados em água. De modo a produzir diferentes teores de austenita reversa, duas das amostras foram revenidas em diferentes temperaturas com resfriamento ao ar, uma à $600^{\circ} \mathrm{C}$ por $30 \mathrm{~min}$, denominada $\mathrm{T} 1$, e outra por $40 \mathrm{~min}$ à $640^{\circ} \mathrm{C}$, denominada $\mathrm{T} 2$. A amostra não revenida foi denominada $\mathrm{T}$ conforme esquematizado na Figura 1.

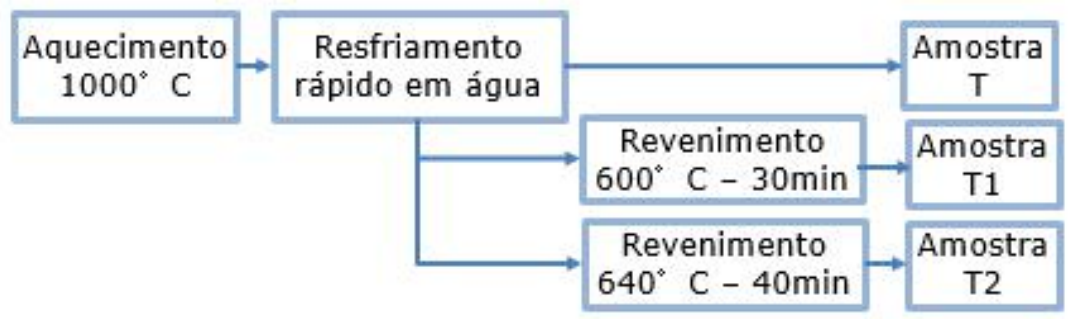

Figura 1 - Fluxograma do tratamento térmico.

A quantificação da austenita nas amostras revenidas foi realizada por espectroscopia Mössbauer após a preparação da superfície com pasta de diamante. A espectroscopia Mössbauer foi realizada em um espectrômetro convencional, com aceleração constante, fonte de ${ }^{57} \mathrm{Co}$ em matriz de Rh mantida à temperatura ambiente usando geometria de espalhamento de elétrons de conversão (CEMS). O sistema Mössbauer utilizado é equipado com um transdutor (CMTE modelo MA250) controlado por uma unidade de comando por função linear (CMTE modelo MR351) e detectores do tipo contador proporcional, utilizando fluxo de gás composto por uma mistura de $95 \% \mathrm{He}$ e $5 \% \mathrm{CH}_{4}$. Os dados experimentais foram ajustados por funções lorentzianas por meio de mínimos quadrados usando o programa NORMOS 90. A microestrutura das três amostras foi caracterizada por microscopia ótica, usando-se o microscópio Olympus, após ataque eletroquímico de $1,5 \mathrm{~V}$ em solução $10 \% \mathrm{v} / \mathrm{v}$ de $\mathrm{HNO}_{3}$.

Antes dos testes eletroquímicos, a superfície das três amostras foi preparada por lixamento progressivo com lixas até 1200 mesh, e caracterizadas por Difração de Raios-X, usando-se o equipamento Pananalytical Empyrean. As fases foram quantificadas pela técnica Rietveld utilizando o programa GSAS e interface EXPGUI. A função de perfil pseudo-Voigt de Thompson-Cox-Hastings foi usada, e o plano de fundo foi ajustado pelo polinômio Chebyschev. Foram realizados, em triplicata, testes eletroquímicos de espectroscopia de impedância eletroquímica e polarização cíclica, usando-se o equipamento AutoLab PGSTAT $100 \mathrm{~N}$ com eletrodo de referência de $\mathrm{Ag} / \mathrm{AgCl}$ e contra eletrodo de platina. Uma solução de tampão borato com $0.3 \mathrm{~mol} / \mathrm{L} \mathrm{H}_{3} \mathrm{BO}_{3}$ e $0.075 \mathrm{~mol} / \mathrm{L} \mathrm{Na}_{2} \mathrm{~B}_{4} \mathrm{O}_{7} .10 \mathrm{H}_{2} \mathrm{O}$ foi utilizada como eletrólito. Para os testes de impedância, foi aplicado potencial com amplitude de $10 \mathrm{mV}$ durante um intervalo de frequência nominal de $10 \mathrm{kHz}$ a $10 \mathrm{mHz}$. Foram feitas 10 leituras por década de frequência. Os testes de polarização potenciodinâmica anódica cíclica foram 
realizados à uma taxa de varredura de $1 \mathrm{mV} / \mathrm{s}$, a partir do potencial de corrosão (Ecorr). A varredura foi revertida ao se alcançar a corrente de $5.10^{-3} \mathrm{~A} / \mathrm{cm}^{2}$ após o potencial de transpassivação.

\section{RESULTADOS E DISCUSSÃO}

A microestrutura das amostras observada com microscópio ótico após ataque é mostrada na Figura 2. O aço é composto basicamente por ripas de martensita, não sendo possível diferenciar partículas de austenita reversa.
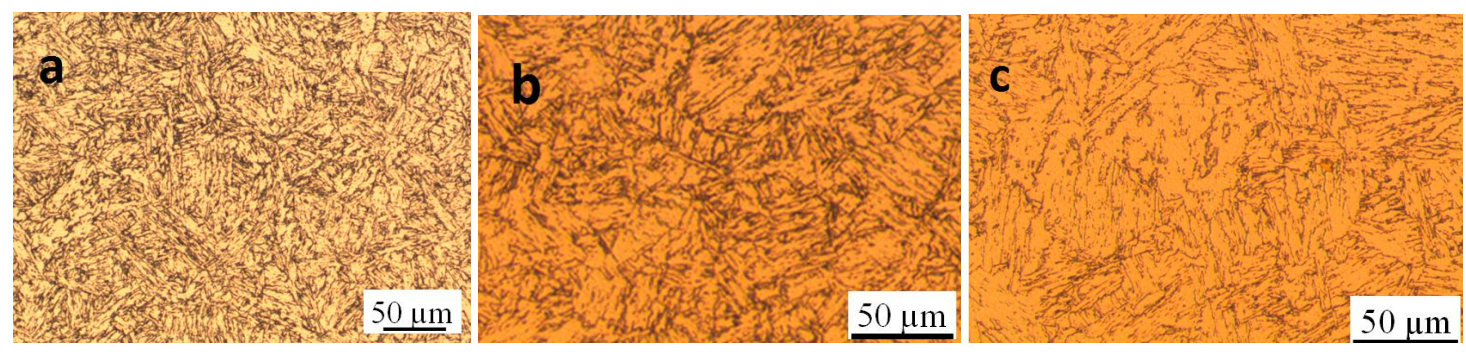

Figura 2 - Micrografia das amostras: a) T; b) T1; c) T2.

A porcentagem de austenita reversa determinada por espectroscopia Mossbauer após o polimento com pasta de diamante está disposta na Figura 3. Considerou-se nulo o teor da amostra $\mathrm{T}$ já que essa amostra não foi revenida, apenas temperada. Como esperado, a amostra $\mathrm{T} 2$, revenida por mais tempo e à uma temperatura mais elevada, apresentou maior teor de austenita, $8 \%$, que a amostra $\mathrm{T} 1$, que apresentou $6 \%$.
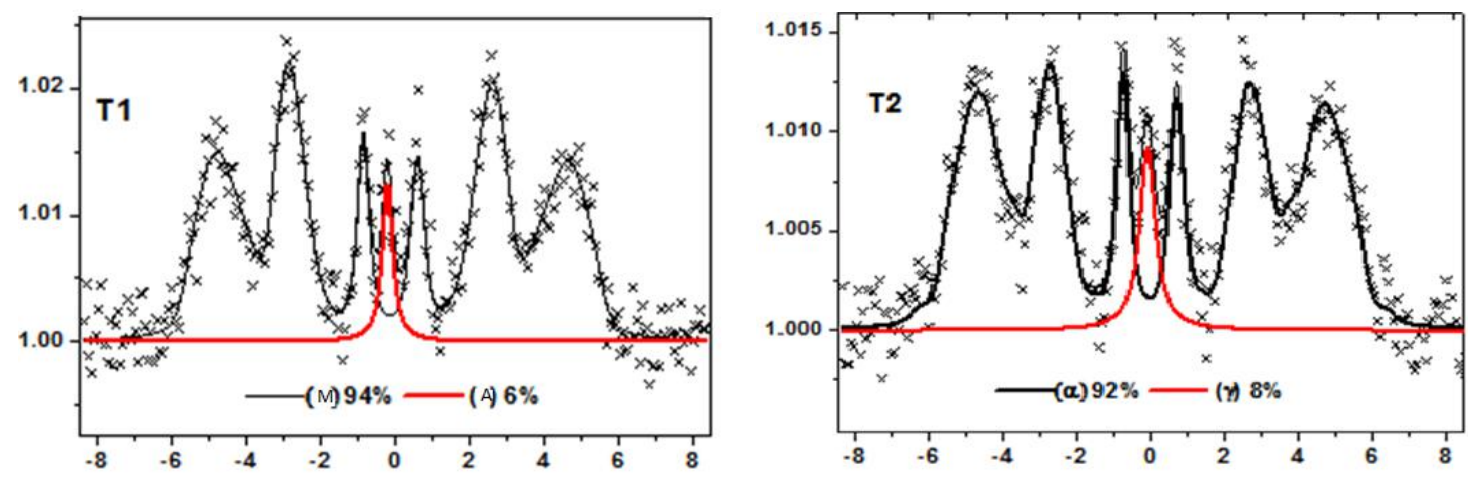

Figura 3 - Espectro obtido por Mossbauer das amostras: a) T1; b) T2.

Os resultados de polarização cíclica estão dispostos na Figura 4, assim como os parâmetros obtidos destacados nos gráficos. Percebe-se que não houve diferença significativa no comportamento das amostras e as curvas estão praticamente sobrepostas. Nesse meio pouco agressivo, o aço não apresentou pite sendo o disparo da densidade de corrente relacionado à dissolução da camada passiva. Pode-se verificar na Figura 4 a existência de uma histerese negativa, indicando que a corrosão localizada por pites é improvável neste meio. 


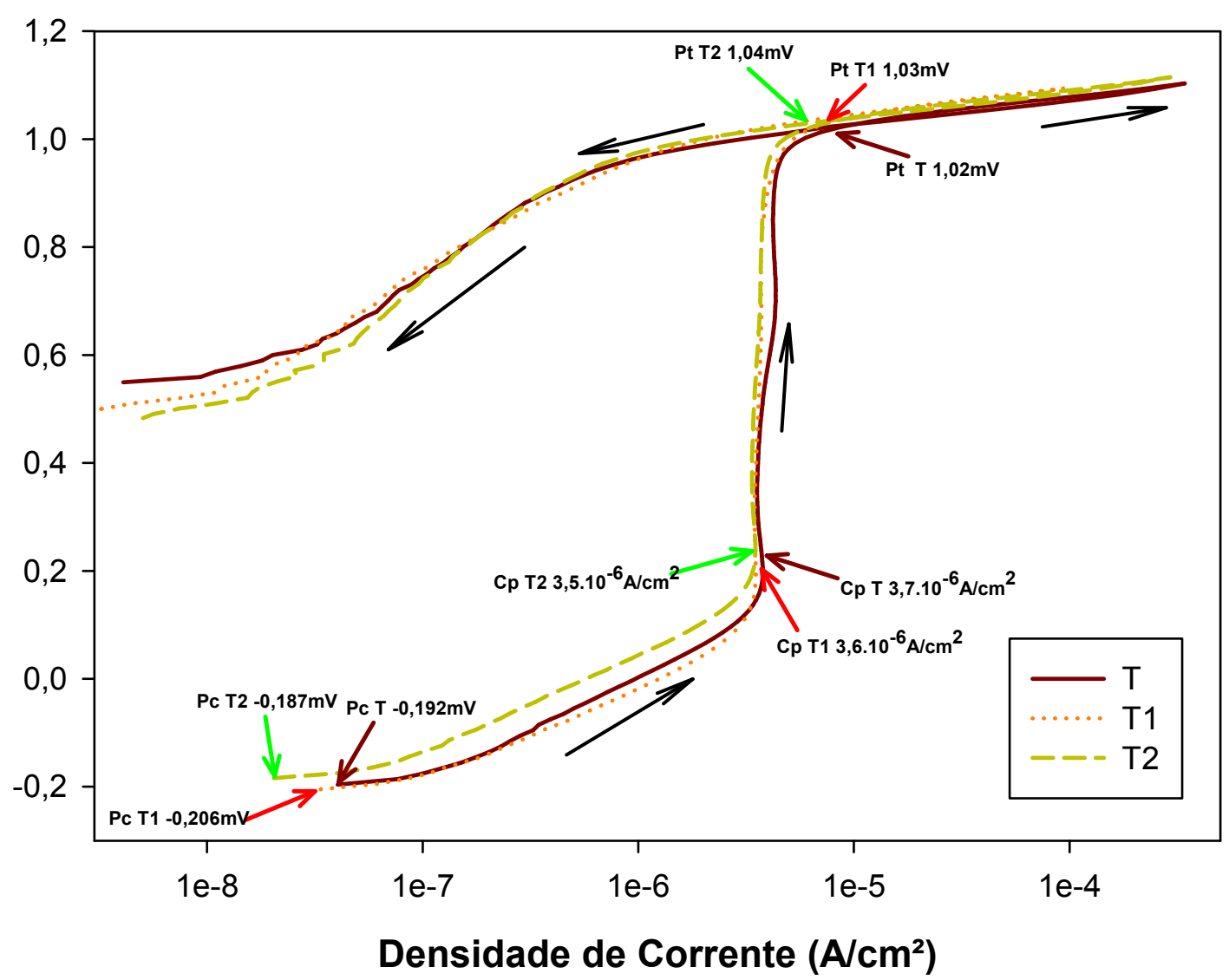

Figura 4 - Resultados dos testes de polarização cíclica das três amostras em tampão borato. $\mathrm{Cp}$ - Corrente de passivação Pc - Potencial de corrosão Pt - Potencial de transpassivação.

Os testes de impedância estão dispostos na Figura 5. A resistência à polarização $(\mathrm{Rp})$ está associada ao processo corrosivo entre o metal e a solução, que ocorre através do filme passivo. Seu valor pode ser obtido através do diâmetro do semicírculo nos gráficos de Nyquist. Mais uma vez os valores de impedância foram similares para as três amostras.

$\mathrm{Na}$ análise, foi considerada uma constante de tempo, com a resistência de polarização tendo a mesma ordem de grandeza para as três amostras. Entretanto, pode-se inferir que a resistência de polarização da amostra de aço sem revenimento (e com teor de austenita reversa de zero) foi inferior à resistência das amostras revenidas. A resistência à corrosão similar das três amostras pode ser explicado com auxílio dos teores de austenita determinados por difração de raios-X, que revelou que as amostras T1 e T2 apresentaram menos que $0,5 \%$ de austenita reversa. Esse baixíssimo valor de austenita, contrário ao resultado por Mossbauer, está possivelmente relacionado à deformação plástica causada pela lixa na preparação das amostras sem a utilização da pasta de diamante para a completa remoção da camada deteriorada. Essa redução da austenita reversa na superfície do aço foi constatada também por Tolchard et al. (2015). Segundo os autores, quanto mais grosseiro o polimento final da superfície maior a retenção da camada deteriorada e, consequentemente, maior a diferença entre o teor de austenita na superfície e no volume da amostra sendo necessário realizar o polimento com pasta de diamante e ou eletropolimento. 


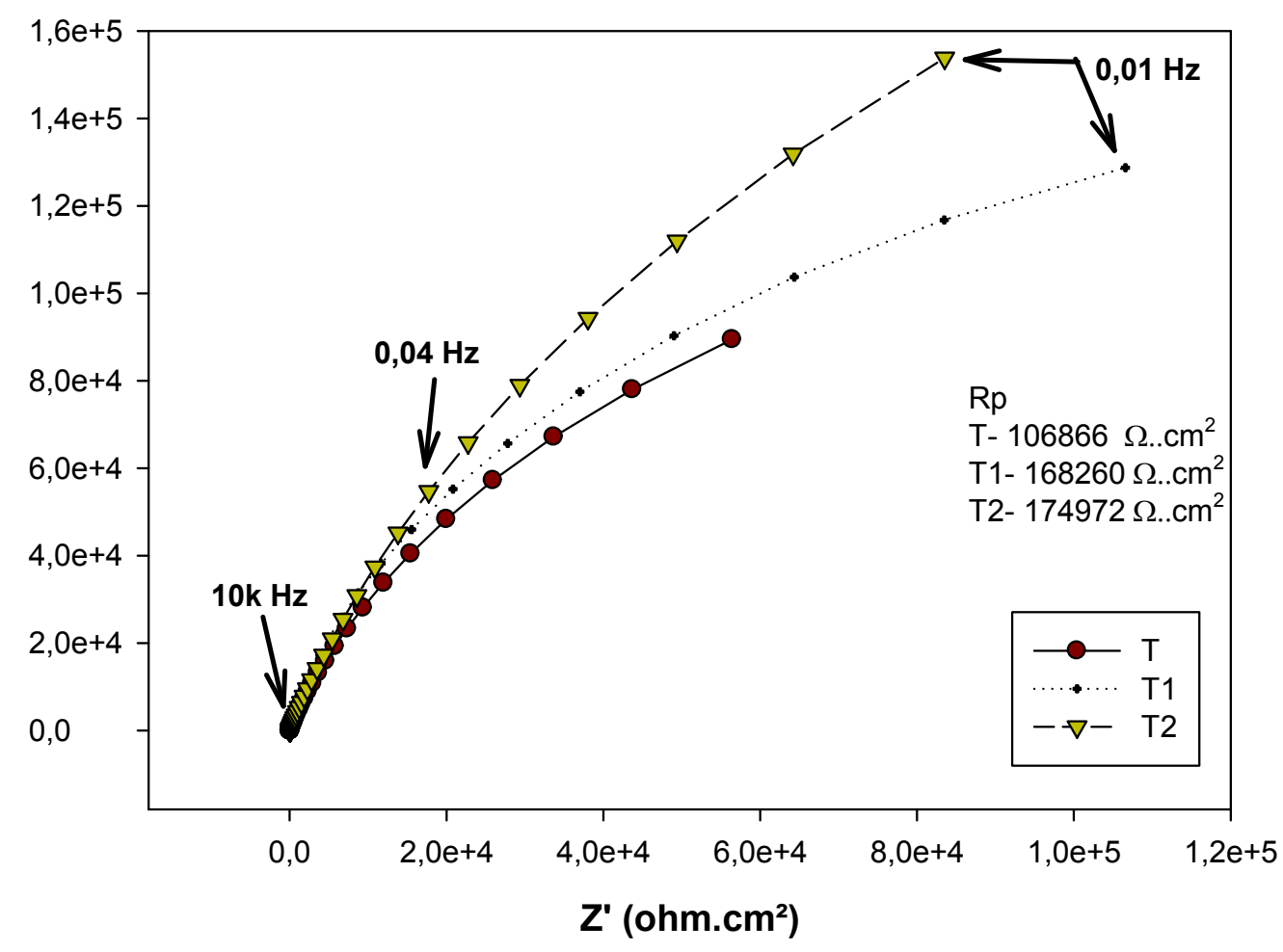

Figura 5 - Diagrama de Nyquist para o aço supermartensítico revenido e não revenido em tampão borato com $0.3 \mathrm{~mol} / \mathrm{L} \mathrm{H}_{3} \mathrm{BO}_{3}$ e $0.075 \mathrm{~mol} / \mathrm{L} \mathrm{Na}_{2} \mathrm{~B}_{4} \mathrm{O}_{7} .10 \mathrm{H}_{2} \mathrm{O}$.

\section{CONCLUSÃO}

As amostras de aço supermartensítico apresentaram microestrutura de fase martensítica. Os resultados da espectroscopia Mossbauer identificaram um teor de $6 \%$ de austenita reversa na amostra revenida a $600^{\circ} \mathrm{C}$ por 30 minutos e um teor de $8 \%$ de austenita reversa na amostra revenida a $640^{\circ} \mathrm{C}$ durante 40 minutos. Nos testes de polarização cíclica, as amostras de aço supermartensítico, revenidas e sem revenimento, apresentaram valores próximos de potencial de transpassivação e corrente de passivação. Os resultados de espectroscopia de impedância eletroquímica indicaram maior resistência à corrosão das amostras revenidas em relação à não revenida.

\section{AGRADECIMENTOS}

Os autores agradecem à CAPES, CNPQ, CDTN, DEQ e DEMET pelo suporte e bolsas de estudo.

\section{REFERÊNCIAS}

BARMOLA, A.; BHINDER, J., Establishing Recrystallization Temperature of Supermartensitic Stainless Steel - A review. In: National Conference on Knowledge, Innovation in Technology and Engineering, 2015, Raipur, Índia.p. 286-289 
DIAS, G. Avaliação da tenacidade à fratura de um aço inoxidável supermartensítico submetido à proteção catódica em água do mar. 2009. 119 f. Dissertação (Mestrado, em Engenharia de Minas, Metalúrgica e de Materiais) - Universidade Federal do Rio Grande do Sul, Porto Alegre, RS, 2009.

KONDO, K.; UEDA, M.; OGAWA, K.; AMAYA, H.; HIRATA, H.; TAKABE, H.; MIYAZAKI, Y.; Alloy design of Super 13Cr martensitic stainless steel (Development of Super $13 \mathrm{Cr}$ martensitic stainless steel for line pipe. In: Proceedings of Supermartensitic Stainless Steels, 1999. Bruxelas: Belgian Welding Institute and Fabrique de Fer, 1999.

KONDO, K.; OGAWA, K.; AMAYA, H.; UEDA, M.; OHTANI, H. Development of Weldable Super 13Cr Martensitic Stainless Steel for Flowline. In: Proceedings of The Twelfth International Offshore and Polar Engineering Conference, 2002, Kitakyushu, Japão, 2002.

LEI, X.; FENG, Y.; ZHANG, J.; FU, A.; YIN, C.; MACDONALD, D. D.; Impact of reversed austenite on the pitting corrosion behavior of super $13 \mathrm{Cr}$ martensitic stainless steel. Electrochimica Acta, v. 191, p. 640-650. 2016.

RODRIGUES, C. A. D.; BANDEIRA, R. M.; DUARTE, B. B.; TREMILIOSI-FILHO, G., JORGE JR., A. M. Effect of phosphorus content on the mechanical, microstructure and corrosion properties of supermartensitic stainless steel. Materials Science and Engineering A, v. 650, p. 75-83. 2016.

TOLCHARD, J. R.; SOMME, A.; SOLBERG J. K.; SOLHEIM, K. G.; On the measurement of austenite in supermartensitic stainless steel by X-ray diffraction. Materials Characterization, v. 99, p. 238-242, 2015.

WEN, J.; KUN-YU, Z.; DONG, Y. E.; JUN, L.; ZHI-DONG, L.; JIE, S. Effect of heat treatment on reversed austenite in Cr15 Super martensitic stainless steel. Journal of Iron and Steel Research International, v.20, n.5, p. 61-65, 2013. 